\title{
EXPRESSION AND CELLULAR DISTRIBUTION OF CYCLIN-DEPENDENT KINASE 4 (CDK4) AND CONNEXIN 43 (CX43) IN PORCINE OOCYTES BEFORE AND AFTER IN VITRO MATURATION
}

\author{
Bartosz KemPISTY ${ }^{1,2}$, Agnieszka ZióŁKowSKA ${ }^{1}$, Hanna PiotrowsKA ${ }^{3 *}$, Paweł AnTosiK ${ }^{4}$, \\ Dorota BUKOWSKA ${ }^{4}$, Piotr ZAWIERUCHA ${ }^{1,2}$, Jędrzej M. JAŚKOWSKI ${ }^{4}$, \\ Klaus-Peter BRÜSSOW ${ }^{5}$, Michał NOWICKI ${ }^{1}$ and Maciej ZABEL ${ }^{1}$ \\ ${ }^{1}$ Department of Histology and Embryology and ${ }^{2}$ Department of Anatomy, \\ Poznań University of Medical Sciences, Poznań, Poland; ${ }^{3}$ Department of Toxicology, \\ Poznań University of Medical Sciences, 30 Dojazd St., 60-631 Poznań, Poland; \\ ${ }^{4}$ Department of Veterinary, Poznań University of Life Sciences, Poznań, Poland; \\ ${ }^{5}$ Department of Reproductive Biology, Leibniz Institute for Farm Animal Biology, \\ Dummerstorf, Germany
}

(Received 27 March 2012; accepted 4 June 2012)

It is recognised that connexin $43(\mathrm{Cx} 43)$ and cyclin-dependent kinase 4 (Cdk4) are involved in the cumulus cell-oocyte communication via gap junctions and the control of cell cycle progress. However, little is known about their mRNA expression pattern and encoded proteins distribution in porcine oocytes during in vitro maturation (IVM). Cumulus-oocyte complexes (COCs) were collected from 31 puberal crossbred Landrace gilts and analysed for their Cdk4 and Cx43 mRNA expression using RQ-PCR and for the respective protein expression by confocal microscopic observations. An increased Cdk4 and $\mathrm{Cx} 43$ mRNA expression was found in oocytes after IVM ( $\mathrm{P}<0.001$ and $\mathrm{P}<0.05$, respectively). Confocal microscopic observations revealed a significant increase of $\mathrm{Cdk} 4$ protein expression in the cytoplasm of oocytes during the maturation process. The localisation of $\mathrm{Cx} 43$ changed from zona pellucida before to cytoplasm of oocytes after IVM. It is supposed that the increased expression of Cdk4 and Cx43 mRNA in oocytes after IVM is linked with the accumulation of a large amount of templates during the process of oocyte maturation. The translocation especially of Cx43 from the zona pellucida into the cytoplasm may be associated with a decrease in gap junction activity in fully grown porcine oocytes. Both Cdk4 and Cx43 can be used as 'checkpoints' of oocyte maturation.

Key words: Cyclin-dependent kinase, connexin, expression, porcine oocyte, in vitro maturation

\footnotetext{
"Corresponding author; E-mail: hpiotrow@ump.edu.pl; Phone: 0048 (61) 847-2081
} 
The maturation of mammalian cumulus-oocyte-complexes (COCs) both in vivo and in vitro is a complex process which includes several fine-tuned molecular, morphological and cellular changes. Up to the MII stage, the maturation process is characterised by the expression of cell-cycle-specific genes and proteins (Chiba, 2011; Schatten and Sun, 2011). Cyclin-dependent kinases (Cdks) are well-described markers of cell cycle control, known also as 'the cell cycle checkpoints'. The cyclin-dependent kinase $4(\mathrm{Cdk} 4)$ is a serine kinase and its activation leads to the phosphorylation of target proteins and thereby promotes cell cycle progression (Berthet and Kaldis, 2006). The complex between Cdk4 and cyclin-D is responsible for the regulation of cell proliferation during the G1 phase. Moreover, Cdk4 is down-regulated by p16, described also as a cyclindependent kinase inhibitor 2 (Cdkn2a) (Feng et al., 2012). The cell cycle regulatory mechanism of Cdk4 was studied mainly in uncontrolled cell proliferation during carcinogenesis (Roberts et al., 2012). However, it is supposed that the cell-cycle-promoting ability of Cdk4 is also involved in the control of cell growth during folliculo- and oogenesis. Cdk4 was found to be involved in G1/S progression during oocyte maturation in mice (Kohoutek et al., 2004).

Another important factor that determines the maturation ability of COCs is the interaction between the surrounding somatic cumulus cells and the oocyte. Both cell types communicate by cell-to-cell transfer of ions, small molecules and second messengers via intercellular channels of gap junctions, which are formed by proteins called connexins (Cxs). The most important proteins crucial for this structure include connexin 37 (Cx37), connexin $43(\mathrm{Cx} 43)$ and connexin 45 (Cx45) (Söhl and Willecke, 2004). Our previous study demonstrated that $\mathrm{Cx} 43$ was differentially localised within oocytes which were recovered from follicles of different size (Antosik et al., 2009; Antosik et al., 2011). Although several data are available on the role of Cdk4 and Cx43 in cell cycle control and cell-tocell communication in mammalian oocytes, especially in oocytes of mice, there is no information on the expression of these genes and the cellular distribution of the respective proteins in porcine oocytes during in vitro maturation. Therefore, the aim of the present study was to compare the Cdk4 and Cx43 mRNA expressions as well as their respective protein distribution in porcine oocytes before and after in vitro maturation (IVM).

\section{Materials and methods}

Animals

A total of 31 crossbred Landrace gilts (mean age: 160 days; mean body weight: $100 \mathrm{~kg}$ ) were used in this study. The experiments were approved by the local Ethics Committee. 
Collection of porcine ovaries and classification of cumulus-oocyte complexes (COCs)

The ovaries were collected after slaughter and transported to the laboratory within $30 \mathrm{~min}$ at $38.5^{\circ} \mathrm{C}$ in $0.9 \% \mathrm{NaCl}$. Thereafter, the ovaries were placed in $5 \%$ fetal bovine serum solution (FBS) (Sigma-Aldrich Co., St. Louis, MO, USA) in phosphate buffered saline (PBS), and COCs were recovered in a sterile Petri dish by puncturing individual follicles $3-5 \mathrm{~mm}$ in size. COCs were washed three times in modified PBS, supplemented with $36 \mu \mathrm{g} / \mathrm{ml}$ pyruvate, $50 \mu \mathrm{g} / \mathrm{ml}$ gentamicin and $0.5 \mathrm{mg} / \mathrm{ml}$ bovine serum albumin (BSA) (Sigma-Aldrich, St. Louis, MO, USA) and then morphologically evaluated under a stereoscopic microscope, using the four-grade scale suggested by Jackowska et al. (2009). Only grade-I COCs $(n=100)$, which have a homogeneous cytoplasm and a complete and compact cumulus oophorus, were used in further steps of the experiment.

Assessment of oocyte developmental competence

by the brilliant cresyl blue (BCB) test

Before in vitro cultivation, oocytes $(\mathrm{n}=100)$ were washed twice in modified Dulbecco's phosphate buffered saline (PBS-DPBS, Sigma-Aldrich Co., St. Louis, MO), supplemented with $50 \mathrm{IU} / \mathrm{ml}$ penicillin, $50 \mu \mathrm{g} / \mathrm{ml}$ streptomycin (Sigma-Aldrich), 0.4\% [w/v] BSA, $0.34 \mathrm{mM}$ pyruvate and $5.5 \mathrm{mM}$ glucose (DPBSm) and then treated with $26 \mu \mathrm{M} \mathrm{BCB}$ (Sigma-Aldrich) diluted in DPBSm at $38.5{ }^{\circ} \mathrm{C}, 5 \% \mathrm{CO}_{2}$ in air for $90 \mathrm{~min}$ according to Wongsrikeao et al. (2006) and Kempisty et al. (2011). After treatment, the oocytes were transferred to DPBSm and washed twice. During the washing procedure, the oocytes were examined under an inverted microscope (Zeiss, Axiovert 35, Lübeck, Germany) and classified as either having stained blue $\left(\mathrm{BCB}^{+}\right)$or remaining colourless $\left(\mathrm{BCB}^{-}\right)$. Only $\mathrm{BCB}^{+}$in a number of approximately $44 \%$, i.e. developmentally competent oocytes, were used for in vitro culture.

In vitro maturation of porcine COCs

The $\mathrm{BCB}^{+}$COCs were cultured in Nunclon ${ }^{\mathrm{TM}} \Delta$ 4-well dishes in $500 \mu \mathrm{l}$ standard porcine IVM culture medium: TCM 199 (tissue culture medium) with Earle's salts and $L$-glutamine (Gibco BRL Life Technologies, Grand Island, NY, USA) supplemented with $2.2 \mathrm{mg} / \mathrm{ml}$ sodium bicarbonate (Nacalai Tesque, Inc., Kyoto, Japan), $0.1 \mathrm{mg} / \mathrm{ml}$ sodium pyruvate (Sigma-Aldrich), $10 \mathrm{mg} / \mathrm{ml} \mathrm{BSA}$ (Sigma-Aldrich, St. Louis, MO, USA), $0.1 \mathrm{mg} / \mathrm{ml}$ cysteine (Sigma-Aldrich), $10 \%(\mathrm{v} / \mathrm{v})$ filtered porcine follicular fluid and gonadotropin supplements at the final concentration of $2.5 \mathrm{IU} / \mathrm{ml} \mathrm{hCG} \mathrm{(Ayerst} \mathrm{Laboratories,} \mathrm{Inc.,} \mathrm{Philadelphia,}$ PA, USA) and $2.5 \mathrm{IU} / \mathrm{ml} \mathrm{eCG}$ (Intervet, Whitby, ON, Canada). Wells were covered with a mineral oil overlay and cultured for $44 \mathrm{~h}$ at $38{ }^{\circ} \mathrm{C}$ under $5 \% \mathrm{CO}_{2}$ in air. 


\section{Real-time quantitative PCR (RQ-PCR) analysis of Cdk4 and CX43 mRNAs expression}

Total RNA was isolated from oocytes before $(\mathrm{n}=40)$ and after IVM $(\mathrm{n}=$ 40), using an RNeasy mini column (Qiagen GmbH, Hilden, Germany) (Kempisty et al., 2008; Kempisty et al., 2009; Jackowska et al., 2009). The RNA samples were resuspended in RNase-free water and stored in liquid nitrogen. RNA samples were treated with DNase I and reverse-transcribed into cDNA. RQ-PCR was conducted in a LightCycler real-time PCR detection system (Roche Diagnostics $\mathrm{GmbH}$, Mannheim, Germany) using $\mathrm{SYBR}^{\circledR}$ Green I as detection dye, and target cDNA was quantified using the relative quantification method. For amplification, cDNA solution was added to QuantiTect ${ }^{\circledR} \mathrm{SYBR}^{\circledR}$ Green PCR Master Mix (Qiagen GmbH, Hilden, Germany) and primers (Table 1). One RNA sample of each preparation was processed without the RT reaction to provide a negative control in the subsequent PCR. To ensure that granulosa cells did not contaminate the oocytes, we demonstrated the absence of cytochrome P450 aromatase transcript by RT and RQ-PCR.

The housekeeping genes glyceraldehyde-3-phosphate dehydrogenase (GAPDH) and $\beta$-actin were amplified as references for mRNA quantification.

In order to quantify specific gene expression in oocytes, the levels of expression of specific oocyte mRNAs in each sample were calculated relative to GAPDH and $\beta$-actin. To ensure the integrity of these results, an additional housekeeping gene, 18S rRNA was used as an internal standard to ensure that GAPDH and $\beta$-actin mRNAs were not differentially expressed in the four morphologically different groups of oocytes. This gene has been identified as an appropriate housekeeping gene for use in quantitative PCR studies (Thellin et al., 1999). The expression of GAPDH and $\beta$-actin did not vary when normalised against 18S rRNA (results not shown).

\section{Confocal microscopic observations}

COCs were isolated from follicles as described above. Oocytes were fixed using $2.5 \%$ paraformaldehyde in PBS and $0.2 \%$ Triton-X 100 for $30 \mathrm{~min}$ at room temperature (RT) and washed three times in PBS/PVP (0.2\%). In order to block nonspecific binding, samples were incubated in 3\% BSA in PBS with $0.1 \%$ Tween-20 for $30 \mathrm{~min}$ at RT. Oocytes were incubated for $12 \mathrm{~h}$ at $4{ }^{\circ} \mathrm{C}$ with rabbit polyclonal anti-Cdk4 antibody (Ab), H-22 or rabbit polyclonal anti-Cx43 $\mathrm{Ab}$ and (Ser 279/282)-R Ab (both from Santa Cruz Biotechnology, Santa Cruz, CA, USA), diluted $1: 500$ in $\mathrm{PBS} / 1.5 \% \mathrm{BSA} / 0.1 \%$ Tween-20. After several washes with PBS/0.1\% Tween-20, samples with rabbit polyclonal anti-Cdk4 Ab and H-22 were incubated for $1 \mathrm{~h}$ at RT with fluorescein isothiocyanate (FITC)-conjugated anti-rabbit IgG Ab produced in goat and diluted 1:500 in PBS/0.1\% Tween-20. Samples with rabbit polyclonal anti-Cx43 Ab and (Ser 279/282)-R Ab were in- 
cubated for $1 \mathrm{~h}$ at RT with fluorescein isothiocyanate (FITC)-conjugated antirabbit IgG $\mathrm{Ab}$ produced in goat and diluted 1:500 in PBS/0.1\% Tween-20. Following washing in PBS $/ 0.1 \%$ Tween-20, the oocytes were mounted on glass slides in antifade drop and observed under LSN 510 confocal system in Olympus microscope, Fluoview 10i. FITC was excited at $488 \mathrm{~nm}$ from an argon laser, and emissions were imaged through a 505-530 nm filter. All 3D confocal microscopic images were analysed using Imaris 7.2 (BitPlane, Zurich, Switzerland) software (Kempisty et al., 2012).

\section{Statistical analysis}

One-way ANOVA followed by Tukey's post hoc test was used to compare the results of real-time RT-PCR quantification. The experiments were carried out in at least three replications. The results quantifying relative abundance (RA) of investigated mRNAs are expressed as the mean of the transcript: GAPDH/ $\beta$-actin/ $18 \mathrm{~S}$ rRNA ratio. The differences were considered to be significant at $\mathrm{P}<0.05$, $\mathrm{P}<0.01$ and $\mathrm{P}<0.001$. The software programme GraphPad Prism version 4.0 (GraphPad Software, San Diego, CA, USA) was used for the statistical calculations.

\section{Results}

RQ-PCR assays revealed both an increased Cdk4 mRNA level $(\mathrm{P}<0.001)$ and $\mathrm{Cx} 43$ mRNA expression $(\mathrm{P}<0.05)$ in oocytes after IVM (Figs 1A and 1B).

Confocal microscopic observations demonstrated both cytoplasmic $(65 \%)$ and zona pellucida distribution of Cdk4 in oocytes before IVM (Fig. 2A). After IVM, a significantly higher expression of this protein was noted in the cytoplasm of oocytes in approximately $90 \%$ of all investigated gametes (Figs $2 \mathrm{~B}, 3 \mathrm{~A}$ and $3 \mathrm{~B})$. The $\mathrm{Cx} 43$ protein showed high zona pellucida localisation in $85 \%$ of the oocytes before IVM, whereas a less intense expression of the protein was observed in the cytoplasm (15\%; Fig. 2C). The oocytes analysed after IVM revealed a strong cytoplasmic distribution of the Cx43 protein in $97 \%$ of the oocytes (Figs 2D, 3C and 3D). The zona pellucida localisation of Cx43 was almost not detectable. The confocal microscopic observation in 3D projection showed a similar expression pattern and distribution of both $\mathrm{Cdk} 4$ and $\mathrm{Cx} 43$ proteins (Figs $3 \mathrm{~A}, 3 \mathrm{~B}, 3 \mathrm{C}$ and 3D). The Cdk4 protein was localised both in the zona pellucida and cytoplasm of oocytes in a similar manner (Figs 3A and 3B).

\section{Discussion}

It has been demonstrated that the maturation of mammalian COCs differs significantly under in vivo and in vitro conditions (Polanski, 1986; Kempisty et 
al., 2012). These differences are strongly influenced by the experimental methods used (Kempisty et al., 2011). Although standard in vitro culture media attempt to mimic the in vivo environment, the efficiency of IVM is still unsatisfactory. In many species, e.g. in dogs, the number of oocytes that reach the MII stage after IVM is less than 10-20\% (Chastant-Maillard et al., 2011). Considering that the maturation process is complex and regulated by several factors, the relationship between the surrounding somatic cells and the oocyte plays a predominant role. This cross-talk is determined by small cell-to-cell connections, i.e. gap junctions, which are formed by connexins. It has been found that both connexins and cyclin-dependent kinases are involved in the regulation of important steps of development and maturation of COCs by paracrine activation of the transport of small substrates and/or by the induction of G2/M transitions, respectively (Valdimarsson et al., 1993; Pant et al., 2005).

A

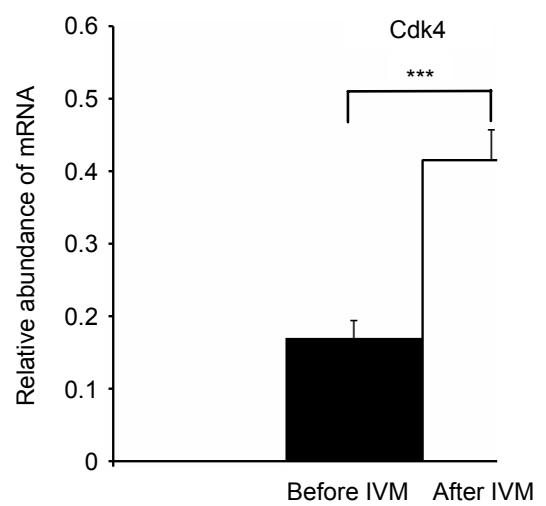

B

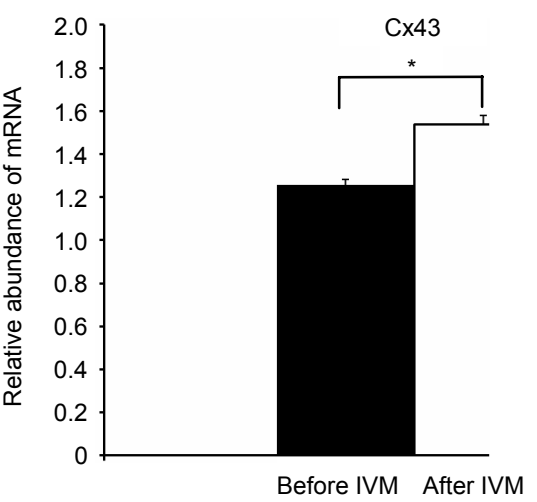

Fig. 1. Relative abundance of Cdk4 and Cx43 mRNAs in porcine oocytes before and after IVM. RNA from porcine oocytes was isolated immediately after recovery of oocytes (before IVM; $n=40$ ), and after in vitro maturation (after IVM; $\mathrm{n}=40$ ). The RNA was reverse-transcribed into cDNA. RQ-PCR was used to evaluate the presence and quantity of Cdk4 (A) and Cx43 (B) transcripts. Each sample was assayed in triplicates. Results are presented as mean $\pm \mathrm{SEM}$ with the level of significance: ${ }^{*} \mathrm{P}<0.05,{ }^{* * *} \mathrm{P}<0.001$ 

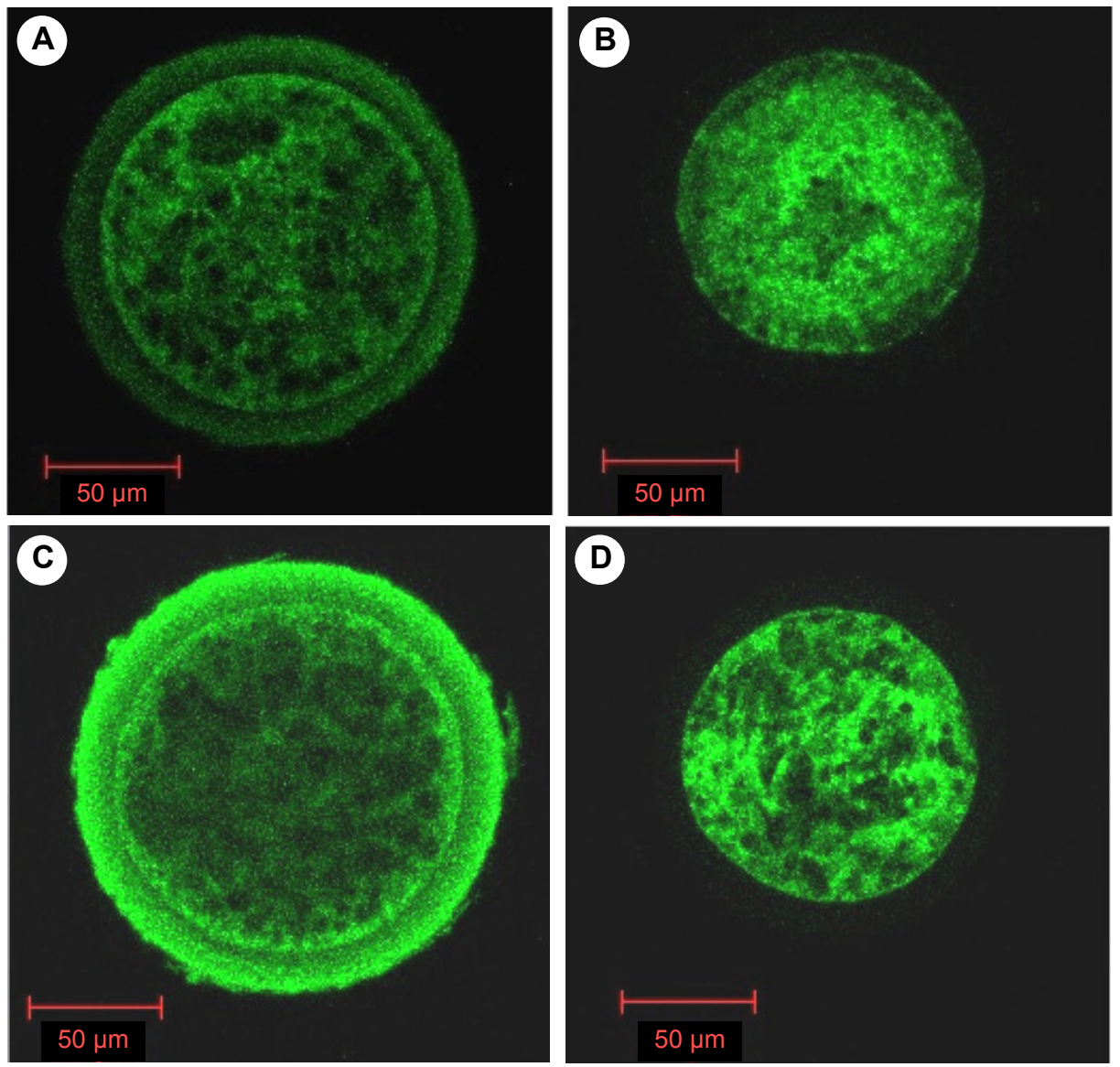

Fig. 2. Localisation of $\mathrm{Cdk} 4$ and $\mathrm{Cx} 43$ proteins in porcine oocytes before and after IVM. Porcine oocytes were stained with (A) porcine Cdk4 (rabbit polyclonal anti-Cdk4 Ab, H-22; Santa Cruz Biotechnology, Santa Cruz, CA, USA). Secondary antibodies were labelled with fluorescein isothiocyanate (FITC) conjugated with goat anti-rabbit antibody $(\mathrm{Ab})$, which emits a green fluorescent signal after excitation at $488 \mathrm{~nm}$, or with (B) porcine $\mathrm{Cx} 43$ (rabbit polyclonal anti-Cx43 $\mathrm{Ab}$, Ser 279/282)-R; Santa Cruz Biotechnology, Santa Cruz, CA, USA). Secondary antibodies were labelled with FITC conjugated with goat anti-rabbit Ab. Scale bars represent $50 \mu \mathrm{m}$ before and after IVM (C and D, respectively)

In several studies using stimulators and/or inhibitors it was shown that connexins induce cumulus cell proliferation and enhance oocyte maturation (Nitta et al., 2010). In a previous study, Kölle et al. (2003) analysed the effect of growth hormone $(\mathrm{GH})$ on the maturation of bovine oocytes and on apoptosis of cumulus cells. They found that GH inhibits the expression and cellular localisation of $\mathrm{Cx} 43$ protein within the cumulus cells. Moreover, the effect of $\mathrm{GH}$ on oocyte maturation was stimulated via gap junction activation, which involves $\mathrm{Cx} 43$ as the main protein forming these connections. The expression of $\mathrm{Cx} 43 \mathrm{mRNA}$ 
was significantly marked in COCs compared to denuded oocytes, and the abundance of Cx43 mRNAs was increased at 0-6 hours of IVM and decreased subsequently (Pandey et al., 2010). These results are in accordance with our findings, where the expression of $\mathrm{Cx} 43$ and of Cdk4 was higher in oocytes after IVM as compared to oocytes analysed before. Additionally, our results from confocal microscopic observations revealed similar protein expression patterns compared to mRNA profiles. The localisation of $\mathrm{Cx} 43$ was displaced from the zona pellucida in oocytes before IVM to a strong cytoplasmic distribution in oocytes analysed thereafter. These observations suggest that $\mathrm{Cx} 43$ may be differentially localised in porcine oocytes dependent on the stage of maturation. Bouvier et al. (2009) described an interaction between $\mathrm{Cx} 43$ and $\mathrm{Cx} 40$, which led to the formation of connexin heterodimers with one protein loop anchored in the cytoplasm. It is suggested that $\mathrm{Cx} 43$ forms a heterodimer structure with $\mathrm{Cx} 40$ in porcine oocytes, which is manifested by a distinct cytoplasmic distribution of $\mathrm{Cx} 43$ after IVM. The significant localisation of $\mathrm{Cx} 43$ in the zona pellucida before IVM may be associated with an increased activity of gap junction transport in not fully grown oocytes which did not reach the MII stage. Contrary to these results, Gittens and Kidder (2005) found that another connexin, Cx37, is involved in the formation of fully competent gametes and has a more important function than $\mathrm{Cx} 43$. They have shown that mouse COCs do not need Cx43 to grow to developmentally competent cells, but $\mathrm{Cx} 37$ seems to be necessary for proper communication between surrounding cumulus-granulosa cells and oocytes during normal oogenesis. However, as opposed to that and in agreement with our results, Teilmann (2005) found in mice COCs that Cx43 may be translocated between cumulus-granulosa cells and oocyte in follicles during the process of preantral to antral transition. Furthermore, the localisation of $\mathrm{Cx} 43$ within the zona pellucida suggests its trans-zonal projection, which would point to new intracellular communications between somatic and germ cells during early folliculogenesis.

The role of cyclins and cyclin-dependent kinases in the cell cycle progression has been investigated in several studies using mammalian oocytes and embryos as well as carcinogenic cell lines (Lequarre et al., 2004; Quetglas et al., 2010; Yue et al., 2012). Among others, the role of cyclins Cdk2 and Cdk4 was analysed in the cell cycle progress during meiotic and mitotic divisions in mouse embryos (Moore et al., 1996). It was found that the abundance of Cdk2 and Cdk4 was increased during the $\mathrm{S}$ and/or $\mathrm{G} 2$ phases of the first mitotic division. Additionally, it was stated that the higher level of Cdk4 mRNA during the first mitotic division was related to polyadenylation, whereas the increased level of Cdk2 and Cdk4 transcripts during the second mitotic division was due to the activation of the embryonic genome. In another study (Zhang et al., 1999), the expression pattern of cyclin D3, Cdk4 and p27 was investigated in the murine testis and ovary. It was suggested that all of these genes and proteins are expressed in these tissues during early development, but are dependent on the stage of maturation and are cell spe- 
cific. However, the expression of cyclin D3 related kinases was detected only in growing tissues and was absent in the fully developed testis and ovary. Our results indicate that $\mathrm{Cdk} 4$ expression significantly increased when comparing oocytes before and after maturation in vitro, which underlines the importance of this protein during oocyte maturation. Like $\mathrm{Cx} 43, \mathrm{Cdk} 4$ was localised both in the zona pellucida and the cytoplasm of oocytes, which implies a possible protein translocation between these two cell structures, depending on the stage of oocyte maturation.
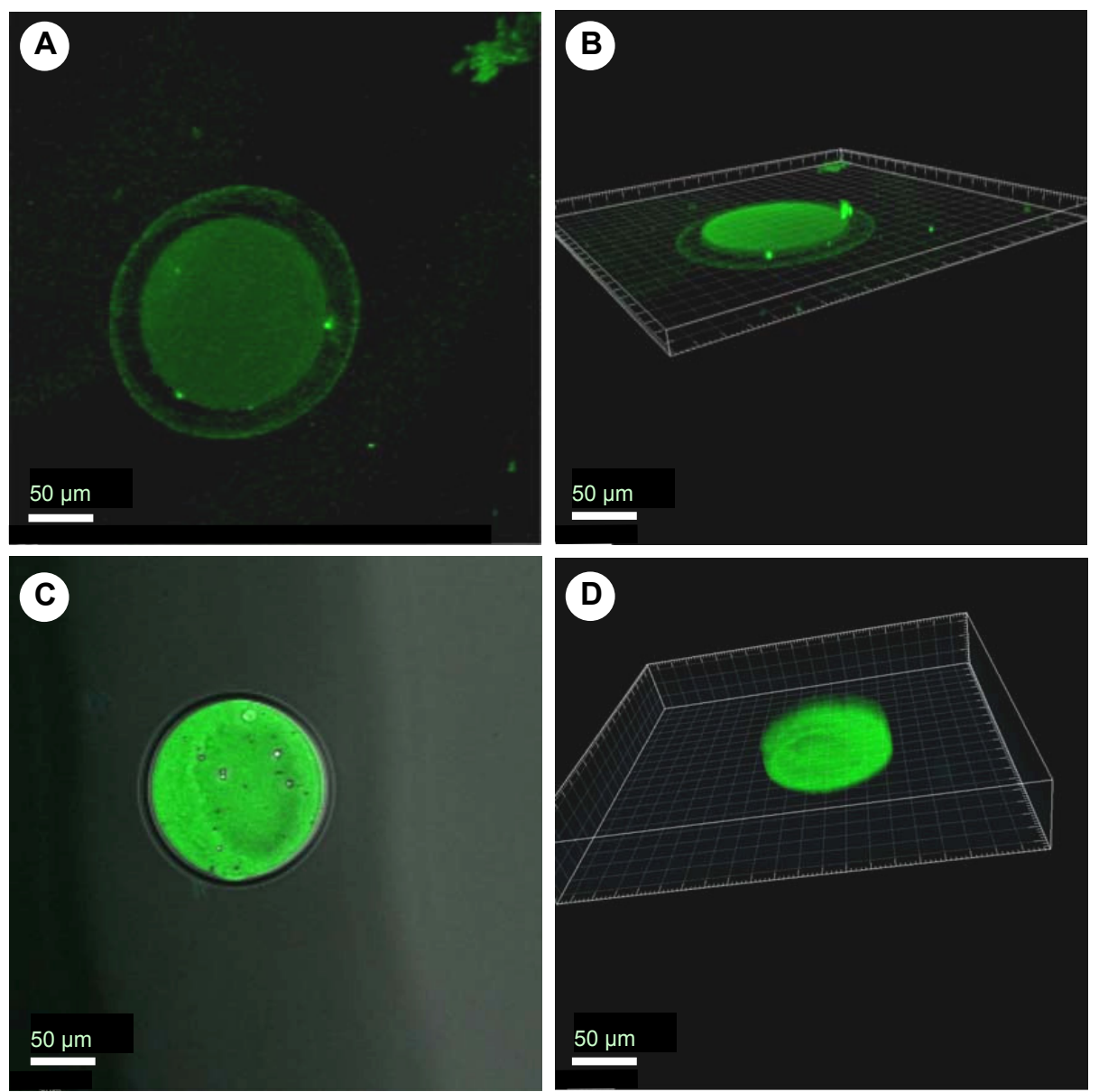

Fig. 3. 3D-confocal microscopic observation of $\mathrm{Cdk} 4$ and $\mathrm{Cx} 43$ distribution within porcine oocytes after IVM. Porcine oocytes $(\mathrm{n}=50)$ were stained after IVM $(\mathrm{A}, \mathrm{B})$ for porcine Cdk4 (rabbit polyclonal anti-Cdk4 Ab, H-22; Santa Cruz Biotechnology, Santa Cruz, CA, USA), and labelled for $1 \mathrm{~h}$ with FITCconjugated goat anti-rabbit IgG $\mathrm{Ab}$ at a 1:500 dilution in PBS. Other porcine oocytes $(\mathrm{n}=50)$ after IVM (C, D) were stained with rabbit polyclonal anti-Cx43 Ab (Ser 279/282-R; Santa Cruz Biotechnology, Santa Cruz, CA, USA), and labelled with FITC-conjugated goat anti-rabbit IgG Ab at a 1:500 dilution in PBS. The confocal microscopic images were analysed by the use of Imaris 7.2 (BitPlane, Zurich, Switzerland) software and presented in 3D projection (B, D). Scale bars represent $50 \mu \mathrm{m}$ 

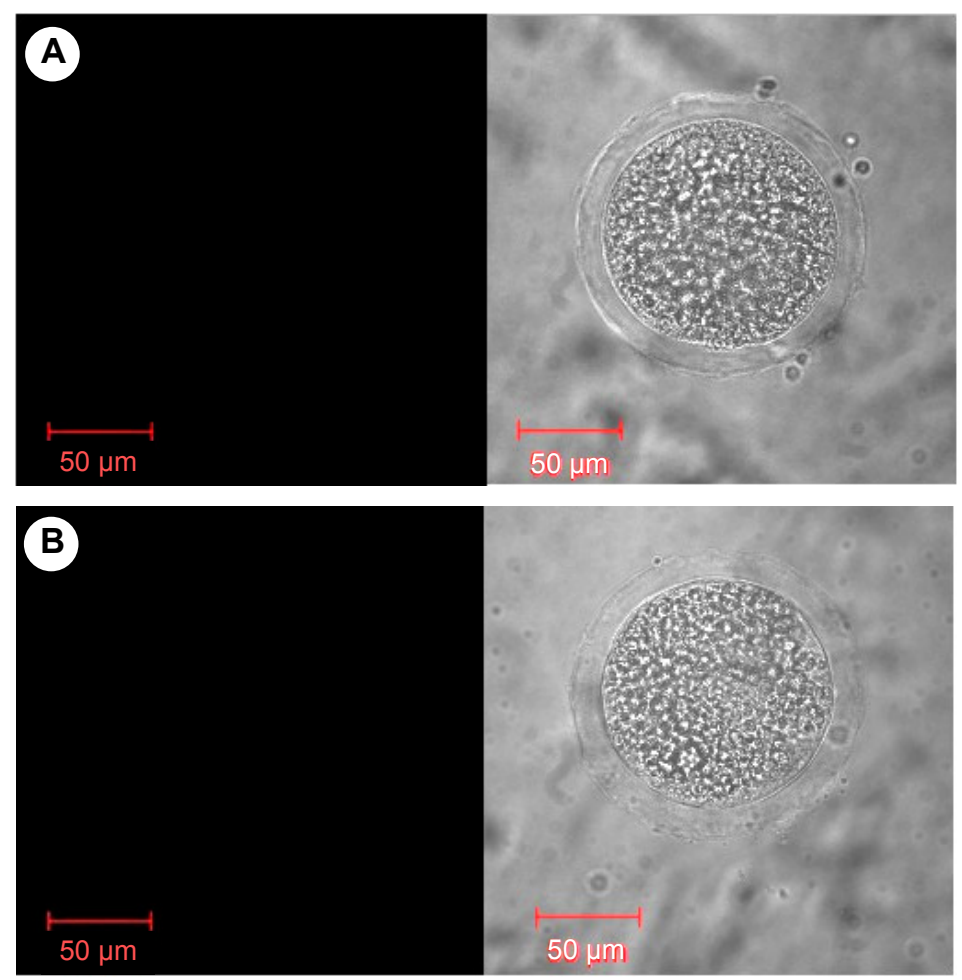

Fig. 4. Confocal microscopic observation of control oocytes. The negative controls, i.e. porcine oocytes with an intact zona pellucida (Figs 4A and 4B), were incubated for $1 \mathrm{~h}$ at room temperature with fluorescein isothiocyanate (FITC)-conjugated goat anti-rabbit IgG Ab at a 1:500 dilution in PBS/0.1\% Tween-20. Following washing in PBS/0.1\% Tween-20, the oocytes were mounted on glass slides in an antifade drop and observed under confocal system. Scale bars represent $50 \mu \mathrm{m}$

In summary, Cdk4 and Cx43 mRNA expression increases in porcine oocytes during the in vitro maturation process and the respective proteins translocate form the oocyte periphery into the cytoplasm. Both Cdk4 and Cx43 can be used as 'checkpoints' of oocyte maturation.

\section{Acknowledgements}

This study was made possible by grant number 0233/IP1/2011/71 'Iuventus Plus' from the Polish Ministry of Scientific Research and Higher Education. The authors wish to acknowledge Dr. Krystyna Filipiak for technical support. 


\section{References}

Antosik, P., Kempisty, B., Bukowska, D., Jackowska, M., Włodarczyk, R., Budna, J., Brüssow, K. P., Lianeri, M., Jagodziński, P. P. and Jaśkowski, J. M. (2009): Follicular size is associated with the levels of transcripts and proteins of selected molecules responsible for the fertilization ability of oocytes of puberal gilts. J. Reprod. Dev. 55, 588-593.

Antosik, P., Kempisty, B., Jackowska, M., Piotrowska, H., Woźna, M., Bukowska, D., Bryja, A., Lianeri, M., Brüssow, K. P. and Jaśkowski, J. M. (2011): Are the levels of Cdk4 and Cx43 proteins of porcine oocytes associated with follicular size? Anim. Biol. 61, 211-224.

Berthet, C. and Kaldis, P. (2006): Cdk2 and Cdk4 cooperatively control the expression of Cdc2. Cell Division doi:10.1186/1747-1028-1-10.

Bouvier, D., Spagnol, G., Chenavas, S., Kieken, F., Vitrac, H., Brownell, S., Kellezi, A., Forge, V. and Sorgen, P. L. (2009): Characterization of the structure and intermolecular interactions between the connexin 40 and connexin43 carboxyl-terminal and cytoplasmic loop domains. J. Biol. Chem. 284, 34257-34271.

Chastant-Maillard, S., Viaris de Lesegno, C., Chebrout, M., Thoumire, S., Meylheuc, T., Fontbonne, A., Chodkiewicz, M., Saint-Dizier, M. and Reynaud, K. (2011): The canine oocyte: uncommon features of in vivo and in vitro maturation. Reprod. Fertil. Dev. 23, 391-402.

Chiba, K. (2011): Evolution of the acquisition of fertilization competence and polyspermy blocks during meiotic maturation. Mol. Reprod. Dev. 78, 808-813.

Feng, X., Hao, J., Liu, Q., Yang, L., Lv, X., Zhang, Y., Xing, L., Xu, N. and Shuxia, Liu (2012): HMGB1 mediates IFN- $\gamma$-induced cell proliferation in MMC cells through regulation of cyclin D1/CDK4/p16 pathway. J. Cell Biochem. doi: 10.1002/jcb.24071.

Gittens, J. E. and Kidder, G. M. (2005): Differential contributions of connexin37 and connexin43 to oogenesis revealed in chimeric reaggregated mouse ovaries. J. Cell Sci. 118, 5071-5078.

Jackowska, M., Kempisty, B., Antosik, P., Bukowska, D., Budna, J., Lianeri, M., Rosińska, E., Woźna, M., Jagodziński, P. P. and Jaśkowski, J. M. (2009): The morphology of porcine oocytes is associated with zona pellucida glycoprotein transcript contents. Reprod. Biol. 9, $79-85$.

Kempisty, B., Antosik, P., Bukowska, D., Jackowska, M., Lianeri, M., Jaśkowski, J. M. and Jagodziński, P. P. (2008): Analysis of selected transcript levels in porcine spermatozoa, oocytes, zygotes and two-cell stage embryos. Reprod. Fert. Dev. 20, 513-518.

Kempisty, B., Antosik, P., Bukowska, D., Jackowska, M., Lianeri, M., Jaśkowski, J. M. and Jagodziński, P. P. (2009): Assessment of zona pellucida glycoprotein and integrin transcript contents in porcine oocytes. Reprod. Biol. 9, 71-78.

Kempisty, B., Jackowska, M., Piotrowska, H., Antosik, P., Woźna, M., Bukowska, D., Brüssow, K. P. and Jaśkowski, J. M. (2011): Zona pellucida glycoprotein 3 (pZP3) and integrin $\beta 2$ (ITGB2) mRNA and protein expression in porcine oocytes after single and double exposure to brilliant cresyl blue test. Theriogenology 75, 1525-1535.

Kempisty, B., Woźna, M., Piotrowska, H., Bukowska, D., Jackowska, M., Antosik, P., Jaśkowski, J. M. and Brüssow, K. P. (2012): The expression of genes encoding zona pellucida glycoproteins in canine cumulus-oocyte complexes cultured in vitro in media supplemented with progesterone and estradiol. Theriogenology 77, 684-693.

Kohoutek, J., Dvorák, P. and Hampl, A. (2004): Temporal distribution of CDK4, CDK6, D-type cyclins, and p27 in developing mouse oocytes. Biol. Reprod. 70, 139-145.

Kölle, S., Stojkovic, M., Boie, G., Wolf, E. and Sinowatz, F. (2003): Growth hormone-related effects on apoptosis, mitosis, and expression of connexin 43 in bovine in vitro maturation cumulus-oocyte complexes. Biol. Reprod. 68, 1584-1589.

Lequarre, A. S., Traverso, J. M., Marchandise, J. and Donnay, I. (2004): Poly(A) RNA is reduced by half during bovine oocyte maturation but increases when meiotic arrest is maintained with CDK inhibitors. Biol. Reprod. 71, 425-431. 
Moore, G. D., Ayabe, T., Kopf, G. S. and Schultz, R. M. (1996): Temporal patterns of gene expression of G1-S cyclins and cdks during the first and second mitotic cell cycles in mouse embryos. Mol. Reprod. Dev. 45, 264-275.

Nitta, M., Yogo, K., Ohashi, M., Akiyama, M., Kunitomo, Y., Ogawa, T., Ishida-Kitagawa, N., Miyoshi, J., Sato, E. and Takeya, T. (2010): Identification and expression analysis of connexin45 and connexin-60 as major connexins in porcine oocytes. J. Anim. Sci. 88, 3269-3279.

Pandey, A., Gupta, S. C. and Gupta, N. (2010): Effect of FSH and LH hormones on oocyte maturation of buffalo and gene expression analysis of their receptors and $\mathrm{Cx} 43$ in maturing oocytes. Zygote 18, 231-234.

Pant, D., Reynolds, L. P., Luther, J. S., Borowicz, P. P., Stenbak, T. M., Bilski, J. J., Weigl, R. M., Lopes, F., Petry, K., Johnson, M. L., Redmer, D. A. and Grazul-Bilska, A. T. (2005): Expression of connexin 43 and gap junctional intercellular communication in the cumulusoocyte complex in sheep. Reproduction 129, 191-200.

Polanski, Z. (1986): In-vivo and in-vitro maturation rate of oocytes from two strains of mice. J. Reprod. Fert. 78, 103-109.

Quetglas, M. D., Adona, P. R., de Bem, T. H., Pires, P. R. and Leal, C. L. (2010): Effect of cyclindependent kinase (CDK) inhibition on expression, localization and activity of maturation promoting factor (MPF) and mitogen activated protein kinase (MAPK) in bovine oocytes. Reprod. Domest. Anim. 45, 1074-1081.

Roberts, P. J., Bisi, J. E., Strum, J. C., Combest, A. J., Darr, D. B., Usary, J. E., Zamboni, W. C., Wong, K. K., Perou, C. M. and Sharpless, N. E. (2012): Multiple roles of cyclin-dependent kinase 4/6 inhibitors in cancer therapy. J. Natl Cancer Inst. 104, 476-487.

Schatten, H. and Sun, Q. Y. (2011): Centrosome dynamics during mammalian oocyte maturation with a focus on meiotic spindle formation. Mol. Reprod. Dev. 78, 757-768.

Söhl, G. and Willecke, K. (2004): Gap junctions and the connexin protein family. Cardiovasc. Res. 62, 228-232.

Teilmann, S. C. (2005): Differential expression and localisation of connexin-37 and connexin-43 in follicles of different stages in the 4-week-old mouse ovary. Mol. Cell Endocrinol. 234, 27-35.

Thellin, O., Zorzi, W., Lakaye, B., De Borman, B., Coumans, B., Hennen, G., Grisar, T., Igout, A. and Heinen, E. (1999): Housekeeping genes as internal standards: use and limits. J. Biotechnol. 75, 291-295.

Valdimarsson, G., De Sousa, P. A. and Kidder, G. M. (1993): Coexpression of gap junction proteins in the cumulus-oocyte complex. Mol. Reprod. Dev. 36, 7-15.

Wongsrikeao, P., Otoi, T., Yamasaki, H., Agung, B., Taniguchi, M., Naoi, H., Shimizu, R. and Nagai, T. (2006): Effects of single and double exposure to brilliant cresyl blue on the selection of porcine oocytes for in vitro production of embryos. Theriogenology 66, 366-372.

Yue, X., Zhang, Z., Liang, X., Gao, L., Zhang, X., Zhao, D., Liu, X., Ma, H., Guo, M., Spear, B. T., Gong, Y. and Ma, C. (2012): Zinc fingers and homeoboxes 2 inhibits hepatocellular carcinoma cell proliferation and represses expression of cyclins A and E. Gastroenterology http://dx.doi.org/10.1053/j.gastro.2012.02.049

Zhang, Q., Wang, X. and Wolgemuth, D. J. (1999): Developmentally regulated expression of cyclin D3 and its potential in vivo interacting proteins during murine gametogenesis. Endocrinology 140, 2790-2800. 